\title{
Viability of Robots in Improving Autistic Student's Engagement and Happiness When Learning
}

\author{
Mohammed J. Yousif ${ }^{1, *}$ \\ ${ }^{1}$ Department of Computer Science, Faculty of Science, Memorial University \\ * Corresponding author: Mohammed J. Yousif, malmutoory@mun.ca
}

\begin{abstract}
The adoption of robotics in other industries is increasing exponentially at a rapid pace due to increased interest in the field. Advancements in robotic technology allow them to be more capable of teaching a variety of topics while costing much less than even just a decade ago. This means that robots are more ready than ever before to be deployed globally in the educational space. This paper aims to check the robots' viability in improving autistic students' engagement and happiness, rather than just their performance. Six autistic students aged 7-12 participated in this experiment (four male and two female). Several different structured scenarios and tasks were used to evaluate the student's happiness and engagement on a scale of five. The children showed an improvement in the happiness rate from $36.6 \%$ to $80 \%$, and increased the engagement rate from $51.6 \%$ to $81.6 \%$. It was also found that the children were showing much more emotion and were much more responsive during the tasks. The Pearson skewness and standard error from the mean showed that the data used in these experiments were consistent and closely distributed to the norm (Mean value).
\end{abstract}

Keywords: Robot Assistant; Robot as Teacher; Autism; Information Analysis; Teaching Method. 


\section{Introduction}

Robotics, alongside other new technologies such as augmented reality/ virtual reality and artificial intelligence, are some of the fastest growing industries in the technological space. They are estimated to make up a staggering $25 \%$ of the worldwide ICT spending by the end of 2023 as shown in Figure 1 (Corporation, 2018).

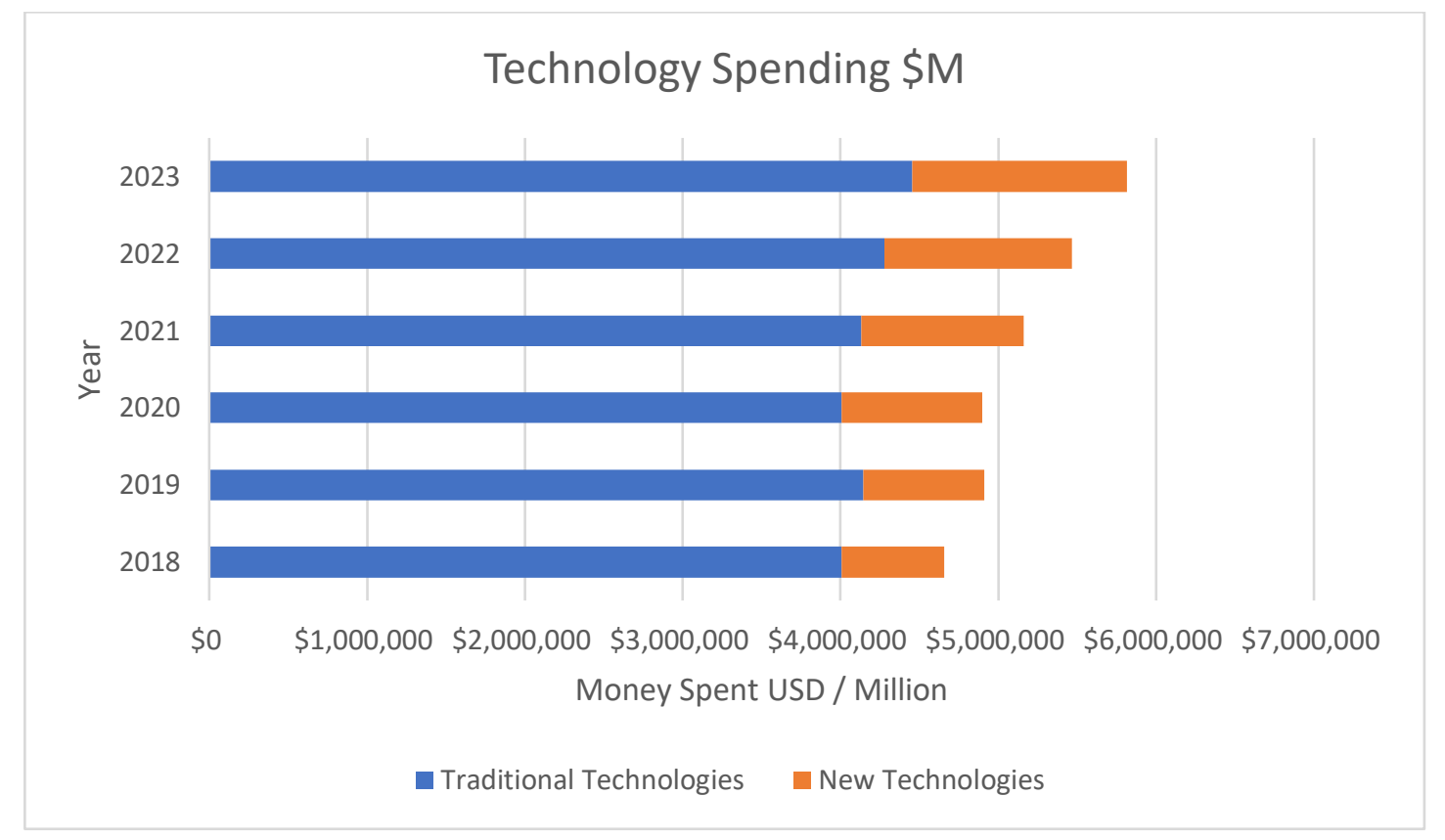

Figure 1: Technology Spending Per Million in the World (Corporation, 2018)

Robotics have expanded their work into many industries' implementation and services, such as the production industry, where they are used in welding cars. Also used in Manufacturing co-bot, stand-alone - articulated, packaging products and performing repetitive tasks at rates that have never before been done by humans. They are also being used in the medical industry to help doctors perform operations with incredible precision and accuracy. Therefore, it is no surprise that robotics has recently started infiltrating the teaching industry. Schools have always followed a primarily teacher-focused method of teaching students. This method is not ideal since the students are forced to memorize rather than learn practically, and they will be bored and not be motivated in class (Catalano \& Catalano, 1999). Robots can create a more student-centered environment since all of the students will get equal attention via multiple robots and can be fitted with accessories such as screens and speakers for a more interactive and memorable 
experience. With their infinite customizability, robotics is, in theory, the perfect tool for use in education since there are so many different types of robots that can each suit a specific function.

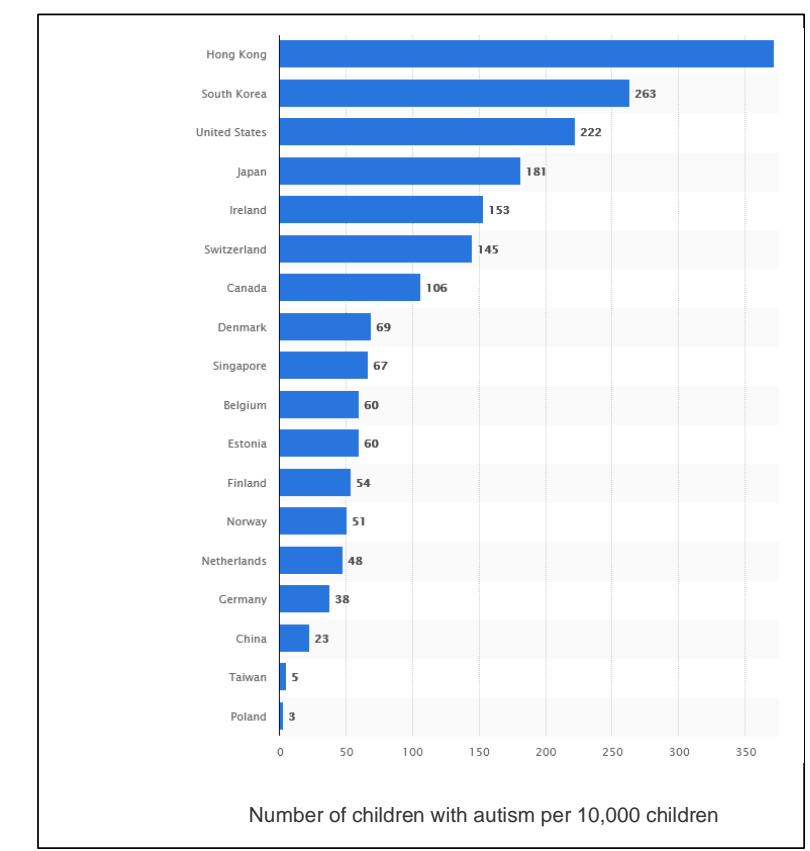

Figure 2: Number of children with autism per 10,000 children studied (Statista, 2020)

It can be seen that in Figure 2, the highest number of cases of autism per 10000 children is in Hong Kong, with 372 cases, followed by South Korea and the United States with 263 and 222 cases respectively, in 2020. Autism is a developmental disorder of varying severity whose symptoms include a difficulty in social interactions, communication and lack of imagination due to sensory overload. This cripples the child's ability to communicate with people around them. To help them, for example, robots can be shaped into a toy with limited facial gestures and movements, so that they can deliver information to autistic students without overloading their senses and improving their responsiveness, imagination and communication. This has been proven to be a big problem with educating autistic students (Kozima, Michalowski, \& Nakagawa, 2009). Another use case is in educating deaf students, where a robot can be equipped with accurate, articulate arms to teach the students sign language. The biggest advantage with robotics is that no training time or costs are necessary, since the same program can be uploaded to many robots at once and they can learn new teaching methods instantly. There are several other papers who have shown the effectiveness of robotics on autistic student's performance as implemented, for example, by (Alemi, Meghdari, Basiri, \& Taheri, 2015). Their results showed that using robotics helped significantly improve autistic children's second language performance (in this case, English). 
The aim of this paper is to check the viability of robots in improving autistic students' engagement and happiness, rather than just their performance. This paper will implement a quantitative methodology due to the majority of the data collected from the experiments being quantitative. This data will interpret and examine the impact of using robots in teaching autistic students based on factors such as engagement, happiness, test scores and video surveillance data.

This paper will be organized in the following sections; Literature Survey, Research Methodology, Experimental Method, Materials and Data, Results and Conclusion.

\section{Literature Survey}

Several researchers investigated the effect of using humanoid robots on autistic students' during exercises. (Scassellati, Admoni, \& Matarić, 2012) organized a systematic review on the use of robots in autism research. Several different types of robots were described, such as KASPAR and Keepon. They also mentioned that most papers regarding this topic usually only have three to tout test subjects due to the limited resources that these experiments have access to, when compared to clinical experiments. They found that most papers where qualitatively rich, as opposed to quantitatively, and that they all follow similar procedures and come to similar conclusions about increased effectiveness in the classroom. (Chiluiza, Alcivar, \& Corredores, 2020) analyzed the effect of Loly, an interactive robot, on student's engagement and information retainment. Twenty children participated in this experiment ( 2 of whom had Asperger syndrome), where they were tasked to play a card game. Their responses and their facial expressions were saved and studied. It was found that children were retraining more information due to them being overall more engaged in the experiment. (Nama, Deb, Debnath, \& Kumari, 2020) deployed a gesture-based robot system, which consists of the humanoid robot NAO and leaps motion gesture technology, to teach special needs children. These children are taught regular academic work that has been slightly modified to incorporate gestures for interaction with the robot. It was found that the playful nature of the NAO robot increased engagement as well as attention during the lessons and that the gesture-based robots are an effective method for teaching special needs children. (So et al., 2019) investigated whether robot-based or human-based learning methods are more suitable for teaching children with low functioning Autism. Children were randomly placed in classes, either with a human tutor or a robot tutor, and their gesture-based learning abilities were then assessed. Children were tested before and after being tutored, and the changes were recorded. It was shown that the type of tutor (human or robot) had no influence on gesture-based learning abilities and that both teaching methods showed similar increases. 
Scassellati (Scassellati, Boccanfuso, et al., 2018) assessed the use of an autonomous social robot to improve autistic children's social skills. Twelve children (five female and seven male) with ASD were told to participate, and 127 hours' worth of data was collected and analyzed. It can be concluded that there was an average $40 \%$ an increase in attention (from 16 to 21 attention score) throughout the experiment; the children all showed more social behavior, increase in listening to instructions, and overall higher engagement. (Kim et al., 2013) evaluated the use of social robots as social behavior reinforcers for children with ASD. Twenty-Four participants with autism aged 4.6 - 12.8 years old participated in an experiment where they are taught by either a computer game, a human tutor, or by Pleo, the social robot. It was found that the children were engaged the most when they were interacting with the robot (20\% more than with the human and $68 \%$ more than with the computer game) and that the robot was just as effective as the human tutor in teaching the children. (Yousif, Kazem, Chaichan, \& Sciences, 2019) explored the use of robotics in educating participants with Autism by deploying a systematic review. They concluded that the social robot is the key to success in most cases that involve teaching students with Autism of varying severities (difficulties in the social association, verbal and non-verbal correspondence, and mental skills) because there is usually a robot (Nao, Pepper, Kaspar, Keepon and Milo) for each case. (Zheng et al., 2013) examined the effect of the NAO robot on autistic children's attention and social skills. The participants were 6 children with ASD with an average of 3.5 years of age. Their results show that as the children got used to the robot, they started to listen to the instructions more and showed an overall increase in their performance. (Kozima, Nakagawa, \& Yasuda, 2005) prepared an experiment to test the interactivity of autistic children with social robots. Several children aged $2-4$ participated in this experiment and the robot that was used was Keepon. It was determined that the robot increased the children's happiness and kept their attention throughout the experiment for all cases.

Hughes (Hughes-Roberts et al., 2019) investigated the effect of a social robots on special needs student's participance and engagement throughout several experiments. The robot that was used was NAO and its effectiveness was tested by 11 participants aged $4-15$ with various forms of special needs (such as Down's syndrome, autism, developmental delay). They found no significant differences in the children's participance and engagement during the experiments when tested with humans versus being tested with the NAO robot (NAO robot had less than 5\% improvement, almost negligent). (Chevalier et al., 2017) tested the effectiveness of using robots to teach children emotional expression via face-mirroring. 20 children aged $4-6$ participated in this experiment and the Zeno robot was their tutor. The writers made the assumption that older autistic children will react similarly to the robot as the 
children that participated in the test. Their results show that all of the children had a lot of fun during the experiment and they managed to emulate the robot and be fully engaged. (Saadatzi, Pennington, Welch, \& Graham, 2018) analyzed the effect of using social robots in teaching autistic adolescents sight words. 2 autistic individuals aged 19 20 took part in this experiment and their tutor was a NAO robot. It was found that not only did the students acquire new words quicker, they also did so with less errors due to the increase in engagement when there is a robot tutor as opposed to a human one. (Pop et al., 2013) compared the effectiveness of using Probo, a social robot versus a computer screen in delivering social stories to children with autism to improve their social skills. 20 children aged $4-9$ were randomly assigned to each method and their results were recorded and compared. It was found that the children tutored by the robot were much more likely be able to complete the task without any prompts or interventions by a human tutor when compared to just using a computer screen.

(Dimitrova, Wagatsuma, Tripathi, \& Ai, 2015) deployed a robot-based case study to examine the effect of using a robot tutor on student's attention and eye gazing patterns. 22 people of varying ages (average of 32) to part in this experiment. They determined that the user paid more attention to the content that was on display when there was a human tutor, while the user paid more attention to the entertainment and communicative aspects of the robot and was distracted from the actual information. (Ioannou, Kartapanis, \& Zaphiris, 2015) investigated the effectiveness of social robots on children with autism. A child with the age of six took part in this experiment and he was tutored by the NAO robot. It was found that there was a significant increase in the quality of the student's education, his social skills and he became more independent. (Scassellati, Brawer, et al., 2018) assessed the effectiveness of using robotics in teaching deaf infants sign language. An unknown number of children aged under one year participated in this test with a custom robot and a virtual avatar on a computer screen. It was found that the infants were smiling at, engaging and learning from the robot without any issues. (Lowe, 2012) evaluated the use of robots in increasing autistics children's engagement when interacting with other people. Two children aged 4-6 participated in this experiment and they were tutored by a custom robot called Troy. It can be concluded that both children, after interaction with robot, showed significantly more engagement with other humans (by up to 220\%) when compared to their engagement before the therapy. (Pakkar, Clabaugh, Lee, Deng, \& Mataricć, 2019) explored the use of the custom robot SPRITE in assisting autistic children with improving their critical thinking skills. There were 8 participants aged $3.5-8$ years old and data of their overall experience was recorded and analyzed. It was found that the children had a lot of fun in the 
exercises when being helped by the robot and the families of these children reported that the robot significantly helped their children.

YAMAN (YAMAN \& ŞIŞMAN, 2018) examined the use of social robots in improving children's interaction level scores. 4 children took part in this experiment, aged six to nine, and they were tutored by the NAO robot. It can be concluded that there was an overall positive attitude towards the robots, and there was a good increase in the children's rate of interaction with other humans around them. (Wang, Hsiao, \& Min, 2016) prepared a survey to simulate a case study to test the effectiveness of using a robot to teach emotional concepts to children with ASD. Thirty-two individuals aged $18-60$ participated in this study involving the Darwin robot. The robot can clearly show several types of emotions and can effectively teach them to autistic children due to its simple design that does not cause any sensory overload. Table 1 presents the literature survey on effects of using humanoid robots on student's performance.

Table 1: Literature Survey on Effects of Using Humanoid Robots on Student's Performance.

\begin{tabular}{|c|c|c|c|}
\hline Auth & Teaching Method & Group & Finding \\
\hline $\begin{array}{c}\text { (Scassellati et } \\
\text { al., 2012) }\end{array}$ & $\begin{array}{l}\text { Multitude of different } \\
\text { types of robots such } \\
\text { as Keepon and } \\
\text { KASPAR }\end{array}$ & $\begin{array}{l}\text { Average of } 4 \\
\text { autistic children } \\
\text { of unknown ages }\end{array}$ & $\begin{array}{l}\text { Most papers where qualitatively rich, as } \\
\text { opposed to quantitatively, and that they all } \\
\text { follow similar procedures and come to } \\
\text { similar conclusions about increased } \\
\text { effectiveness in the classroom. }\end{array}$ \\
\hline $\begin{array}{l}\text { (Chiluiza et } \\
\text { al., 2020) }\end{array}$ & Loly cus & $\begin{array}{l}20 \text { children aged } 4 \\
-6 \text { ( } 2 \text { of them } \\
\text { having Asperger } \\
\text { syndrome })\end{array}$ & $\begin{array}{l}\text { Children were retraining more information } \\
\text { due to them being overall more engaged in } \\
\text { the experiment. }\end{array}$ \\
\hline $\begin{array}{r}\text { (Nama e } \\
2020\end{array}$ & $\begin{array}{l}\text { ot and Leap } \\
\text { sture } \\
\text { y }\end{array}$ & $\begin{array}{l}\text { Special needs } \\
\text { children of } \\
\text { unspecified ages. }\end{array}$ & $\begin{array}{l}\text { The NAO robot increased engagement and } \\
\text { attention during the lessons. Gesture-based } \\
\text { robots are useful in teaching special needs } \\
\text { children. }\end{array}$ \\
\hline (So & NAO & Children ag & $\begin{array}{l}\text { Children tutored by the robot saw an increase of } \\
25 \% \text { in gestural recognition and up to } 250 \% \\
\text { increase in gestural production. }\end{array}$ \\
\hline $\begin{array}{l}\text { (Scassellati, } \\
\text { Boccanfuso, } \\
\text { et al., 2018) }\end{array}$ & $\begin{array}{l}\text { Unspecified } \\
\text { autonomous social } \\
\text { robot }\end{array}$ & $\begin{array}{l}n(5 \\
7 \\
\text { ASD }\end{array}$ & $\begin{array}{l}\text { There was an average } 40 \% \text { increase in } \\
\text { attention (from } 16 \text { to } 21 \text { attention score) } \\
\text { throughout the experiment, the children all } \\
\text { showed more social behavior, increase in } \\
\text { listening to instructions and overall higher } \\
\text { engagement. }\end{array}$ \\
\hline $\begin{array}{c}\text { (Kim et al., } \\
\text { 2013) }\end{array}$ & Pleo social robot & $\begin{array}{l}24 \text { participants } \\
\text { with autism aged } \\
4.6-12.8 \text { years } \\
\text { old. }\end{array}$ & $\begin{array}{l}\text { Children were engaged the most when they } \\
\text { were interacting with the robot ( } 20 \% \text { more } \\
\text { than with the human and } 68 \% \text { more than } \\
\text { with the computer game) and that the robot } \\
\text { was just as effective as the human tutor in } \\
\text { teaching the children. }\end{array}$ \\
\hline $\begin{array}{c}\text { (Yousif et al., } \\
\text { 2019) }\end{array}$ & $\begin{array}{l}\text { Multitude of different } \\
\text { types of robots such } \\
\text { as NAO, KASPAR, } \\
\text { Milo }\end{array}$ & $\begin{array}{l}\text { Autistic } \\
\text { participants of } \\
\text { unknown ages or } \\
\text { numbers }\end{array}$ & $\begin{array}{l}\text { Social robot is the key to success in most } \\
\text { cases that involve teaching students with } \\
\text { Autism of varying severities }\end{array}$ \\
\hline
\end{tabular}




\begin{tabular}{|c|c|c|c|}
\hline $\begin{array}{l}\text { (Zheng et al., } \\
\text { 2013) }\end{array}$ & NAO robot & $\begin{array}{l}6 \text { autistic children } \\
\text { with average age } \\
\text { of } 3.5 \text { years old }\end{array}$ & $\begin{array}{l}\text { As the children got used to the robot, they } \\
\text { started to listen to the instructions more and } \\
\text { showed an overall increase in their } \\
\text { performance. }\end{array}$ \\
\hline $\begin{array}{l}\text { (Kozima et } \\
\text { al., 2005) }\end{array}$ & Keepon robot & $\begin{array}{l}\text { Autistic children } \\
\text { aged } 2-4 \text { of } \\
\text { unknown numbers }\end{array}$ & $\begin{array}{l}\text { The robot increased the children's } \\
\text { happiness and kept their attention } \\
\text { throughout the experiment for all cases. }\end{array}$ \\
\hline $\begin{array}{l}\text { (Hughes- } \\
\text { Roberts et al., } \\
\text { 2019) }\end{array}$ & NAO robot & $\begin{array}{l}11 \text { special needs } \\
\text { students aged } 4 \text { - } \\
15\end{array}$ & $\begin{array}{l}\text { There were no significant differences in the } \\
\text { children's participance and engagement } \\
\text { during the experiments when tested with } \\
\text { humans versus being tested with the NAO } \\
\text { robot (NAO robot had less than } 5 \% \\
\text { improvement, almost negligent). }\end{array}$ \\
\hline $\begin{array}{l}\text { (Chevalier et } \\
\text { al., 2017) }\end{array}$ & Zeno robot & $\begin{array}{l}20 \text { children aged } 4 \\
-6\end{array}$ & $\begin{array}{l}\text { All of the children had a lot of fun during } \\
\text { the experiment and they managed to } \\
\text { emulate the robot and be fully engaged. }\end{array}$ \\
\hline $\begin{array}{l}\text { (Saadatzi et } \\
\text { al., 2018) }\end{array}$ & NAO robot & $\begin{array}{l}2 \text { autistic } \\
\text { individuals aged } \\
19-20\end{array}$ & $\begin{array}{l}\text { Not only did the students acquire new } \\
\text { words quicker, they also did so with less } \\
\text { errors due to the increase in engagement } \\
\text { when there is a robot tutor as opposed to a } \\
\text { human one. }\end{array}$ \\
\hline $\begin{array}{l}\text { (Pop et al., } \\
\text { 2013) }\end{array}$ & Probo robot & $\begin{array}{l}20 \text { children with } \\
\text { ASD aged } 4-9\end{array}$ & $\begin{array}{l}\text { Children tutored by the robot were much } \\
\text { more likely be able to complete the task } \\
\text { without any prompts or interventions by a } \\
\text { human tutor when compared to just using a } \\
\text { computer screen. }\end{array}$ \\
\hline $\begin{array}{l}\text { (Dimitrova et } \\
\text { al., 2015) }\end{array}$ & NAO robot & $\begin{array}{l}22 \text { individuals } \\
\text { with a mean age } \\
\text { of } 32\end{array}$ & $\begin{array}{l}\text { The user payed more attention to the } \\
\text { content that was on display when there was } \\
\text { a human tutor, while the user payed more } \\
\text { attention to the entertainment and } \\
\text { communicative aspects of the robot and was } \\
\text { distracted from the actual information. }\end{array}$ \\
\hline $\begin{array}{l}\text { (Ioannou et } \\
\text { al., 2015) }\end{array}$ & NAO robot & $\begin{array}{l}\text { Child aged } 6 \text { with } \\
\text { ASD }\end{array}$ & $\begin{array}{l}\text { There was a significant increase in the } \\
\text { quality of the student's education, his social } \\
\text { skills and he became more independent. }\end{array}$ \\
\hline $\begin{array}{l}\text { (Scassellati, } \\
\text { Brawer, et } \\
\text { al., 2018) }\end{array}$ & Unspecified robot & $\begin{array}{l}\text { Deaf children } \\
\text { under } 1 \text { years old } \\
\text { of unknown } \\
\text { numbers }\end{array}$ & $\begin{array}{l}\text { The infants were smiling at, engaging and } \\
\text { learning from the robot without any issues. }\end{array}$ \\
\hline (Lowe, 2012) & Troy custom robot & $\begin{array}{l}2 \text { children with } \\
\text { ASD aged } 4-6 \\
\text { years old }\end{array}$ & $\begin{array}{l}\text { Both children, after interaction with robot, } \\
\text { showed significantly more engagement } \\
\text { with other humans (by up to } 220 \% \text { ) when } \\
\text { compared to their engagement before the } \\
\text { therapy. }\end{array}$ \\
\hline $\begin{array}{l}\text { (Pakkar et } \\
\text { al., 2019) }\end{array}$ & $\begin{array}{l}\text { SPRITE custom } \\
\text { robot }\end{array}$ & $\begin{array}{l}8 \text { children with } \\
\text { ASD aged } 3.5-8 \\
\text { years old }\end{array}$ & $\begin{array}{l}\text { Children had a lot of fun in the exercises } \\
\text { when being helped by the robot and the } \\
\text { families of these children reported that the } \\
\text { robot significantly helped their children. }\end{array}$ \\
\hline $\begin{array}{l}\text { (YAMAN \& } \\
\text { ŞiŞMAN, } \\
\text { 2018) }\end{array}$ & NAO robot & $\begin{array}{l}4 \text { children with } \\
\text { autism aged } 6 \text { - } 9 \\
\text { years old }\end{array}$ & $\begin{array}{l}\text { There was an overall positive attitude } \\
\text { towards the robots and there was a good } \\
\text { increase in the children's rate of interaction } \\
\text { with other humans around them. }\end{array}$ \\
\hline $\begin{array}{l}\text { (Wang et al., } \\
\text { 2016) }\end{array}$ & Darwin robot & $\begin{array}{l}32 \text { individuals } \\
\text { aged } 18-60\end{array}$ & $\begin{array}{l}\text { The robot can clearly show several types of } \\
\text { emotions and can effectively teach them to } \\
\text { autistic children due to its simple design } \\
\text { that does not cause any sensory overload. }\end{array}$ \\
\hline
\end{tabular}




\section{Research Methodology}

This paper aims to find if there is a significant and measurable difference in autistic students' happiness and engagement levels when being taught by a humanoid robot. This paper will implement a quantitative methodology based on a one group pretest-posttest approach due to the majority of the data collected from the experiments being quantitative. This data will interpret and examine the impact of using robots in teaching autistic students based on factors such as engagement, happiness, test scores and video surveillance data. The number of participants was low so they all had to be grouped into one group. This paper deploys the Engagement and Happiness Testing Framework, as shown in Figure 3. There are three stages, Information and retention testing, observation and happiness testing. In the third stage, students are asked to do a series of tasks and then rate their overall experience on a scale of 5 to determine their happiness. An engagement score was determined by combining data relating to their test scores as well as data relating to patterns in their behavior when performing these tasks which was obtained by analyzing video recordings of the experimental sessions. The reason for using video recording is because it provides us with more data to more accurately gage the student's level of engagement, rather than relying on test scores alone. Then, similar tasks are repeated again but a humanoid robot instructor will be used alongside the human tutor. The students will then rate their second experience, on the same scale, and a new engagement score will be calculated. The old and new scores will then be compared so that brief conclusions can be made regarding the effect of humanoid robots on autistic students' engagement and happiness.

\section{Experimental Method}

The experiment consists of three stages, a teaching stage, an observation stage, and a happiness stage. The whole experiment takes place in an empty room, and each student is tested individually rather than together to reduce any distractions and changing variables between each student.

In the first stage, the students are first taught about a wide variety of topics by a human tutor, for example, teaching them road signs, matching fruits with their names, solving simple mathematical questions, and the like. The students are then given a quiz, where they have to solve as many questions as possible in a limited amount of time. This quiz 
includes questions that test all of the topics that were taught in an earlier session. This is to test if there is any information retention from the previous session. If the children were not able to finish in time, the quiz was removed. The quiz results were then divided by 4 (so that they are on a scale of 5) and rounded to the nearest whole number. In the second stage, the students are accompanied by a human tutor, where they are taught several different dance techniques and hand gestures and are asked to mimic the tutor. Throughout both stages, a camera in the corner of the room records all of the events that are taking place. The videos are then analyzed and examined to give a video surveillance score for each student.
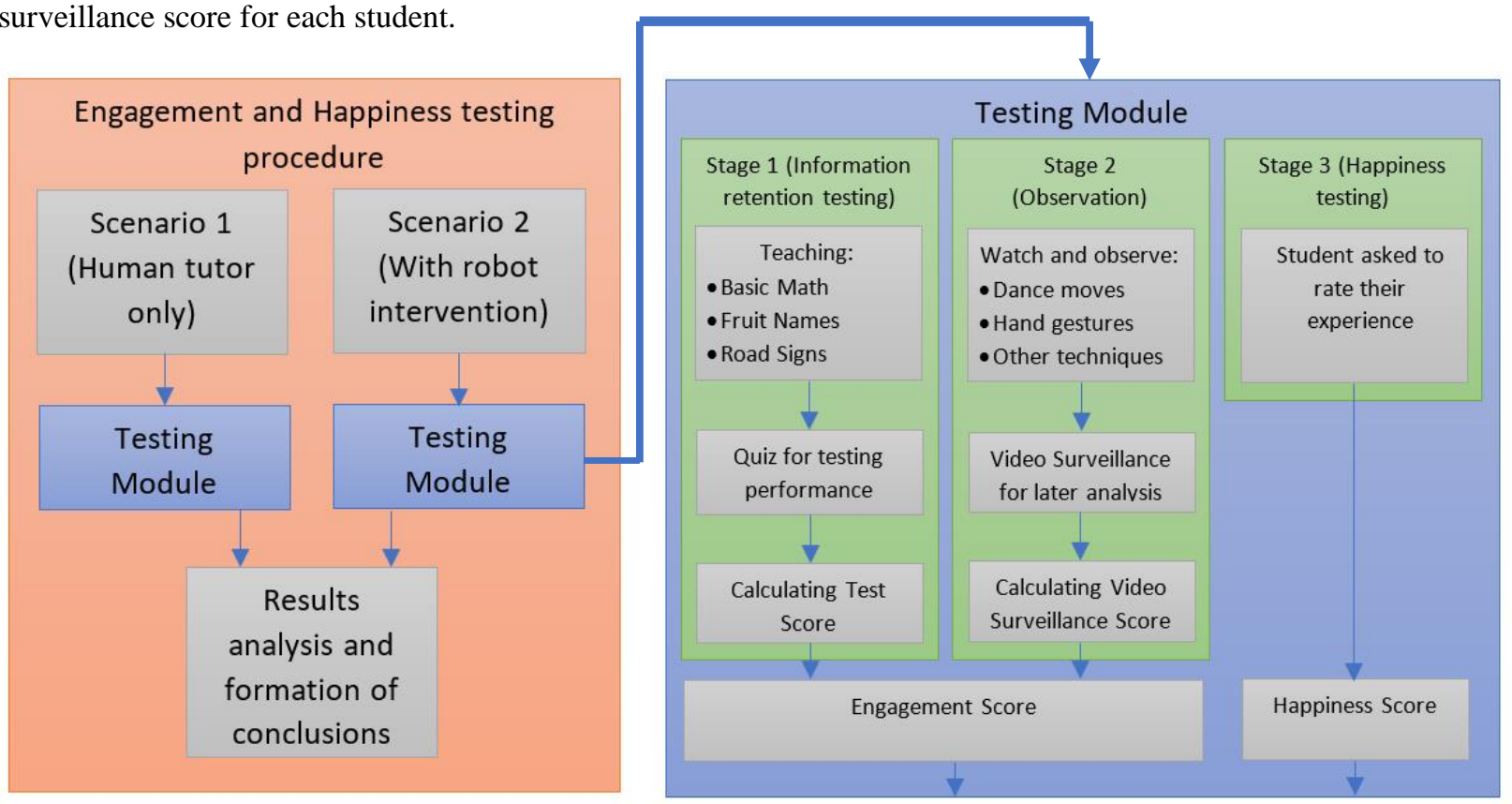

Figure 3: Engagement and Happiness Testing Framework.

The video surveillance score is also on a 5-point scale and each score reflects how the student acts during both stages as shown in Table 2. This score as well as the test score from the previous stage are then averaged and used to calculate the engagement score.

Table 2: Video Surveillance Scores and Their Corresponding Meaning.

\begin{tabular}{ll}
\hline Points & How the student acted during the experiment \\
\hline $\mathbf{1}$ & The student refused to acknowledge/ follow any of the instructions that were \\
& given to them. \\
$\mathbf{2}$ & The student only followed a few of the instructions with a lot of reluctance. \\
$\mathbf{4}$ & The student followed most of the instructions with some reluctance. \\
& The student followed most of the instructions, but more excitement / eagerness is \\
$\mathbf{5}$ & shown during the experiment. \\
& The student followed all of the instructions correctly and exhibited normal, non- \\
& autistic behavior.
\end{tabular}


After both stages are over, the third stage begins. Here, the student is asked to rate their experience on a scale of 5 , with one corresponding to a sad experience and 5 corresponding to a very enjoyable experience. This score is the happiness score. The children were not pressured in any way and were given as much time as they needed to give this score, so as to not sway their opinions. This whole procedure is then repeated again, but instead a humanoid robot instructor, NAO, will accompany the human tutor during the stages. NAO is a humanoid robot that was developed by SoftBanks robotics. It was programmed to do many tasks like picture recognition, dancing, gestures, showing emotions and talking using the Choregrpahe IDE that was bundled with the robot. The robot was a multitude of features such as many motors, cameras, LEDs and a toy like shape to make all of these tasks possible. All of the gathered scores were then neatly arranged together, as shown in Table 4.

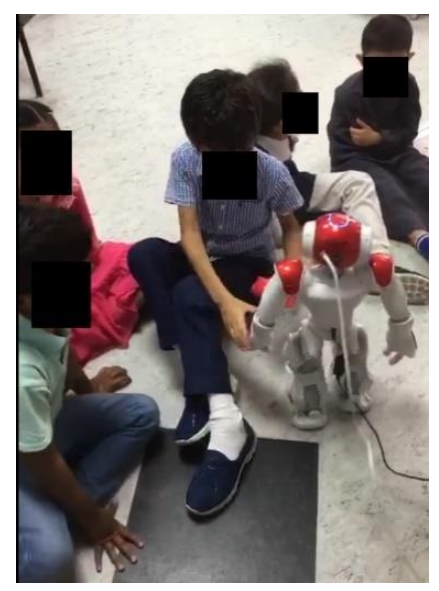

Figure 4: NAO Humanoid Robot Interacting with Students in the Experiment.

\section{Materials and Data}

All of the children and their parents were explicitly told that data about their children will be collected and video surveillance will take place. All of the children and their parents agreed for these experiments to take place under these conditions. The children were brought from a center that educates autistic students that is located in Oman. There were not that many students in the center, and of those children, only six children's families agreed to the requirements of this paper (recording and testing). The students were all pretested in the center for autistic students, and all of the students who were picked for the experiment had very similar autism spectrum scores. This is to ensure that the children's scores were not affected by the severity of their autism. Table 3 has information about the students. 
Table 3: Information About Participants.

\begin{tabular}{llll}
\hline Participants & Age & Gender & Disability \\
\hline A & 12 & Male & Autism \\
B & 10 & Female & Autism \\
C & 10 & Male & Autism \\
D & 8 & Male & Autism \\
E & 8 & Female & Autism \\
F & 7 & Male & Autism \\
\hline
\end{tabular}

Table 4 presents the all of the scores for all of the students in each scenario. The engagement score was calculated by finding the average of the test score and the video surveillance score. The video surveillance score was calculated by observing the recorded footage of all of the children in each scenario and focusing on things like their facial expressions, their willingness to answer instructor's questions and listen to his requests.

Table 4: Participants Scores for all Tested Scenarios and Stages.

\begin{tabular}{|c|c|c|c|c|c|c|c|}
\hline $\begin{array}{l}\text { Type of } \\
\text { Score }\end{array}$ & $\begin{array}{c}\text { Before / } \\
\text { After robot } \\
\text { intervention }\end{array}$ & & & Partic & Score & & \\
\hline & & $\mathrm{A}$ & $\mathrm{B}$ & $\mathrm{C}$ & $\mathrm{D}$ & $E$ & $\mathrm{~F}$ \\
\hline \multirow{2}{*}{ Happiness } & Before & 2 & 1 & 2 & 1 & 3 & 2 \\
\hline & After & 4 & 3 & 4 & 4 & 5 & 4 \\
\hline Video & Before & 2 & 1 & 2 & 1 & 2 & 2 \\
\hline Surveillance & After & 3 & 3 & 3 & 4 & 5 & 3 \\
\hline \multirow[t]{2}{*}{ Test } & Before & 3 & 4 & 3 & 3 & 4 & 4 \\
\hline & After & 5 & 5 & 4 & 5 & 4 & 5 \\
\hline \multirow{2}{*}{ Engagement } & Before & 2.5 & 2.5 & 2.5 & 2 & 3 & 3 \\
\hline & After & 4 & 4 & 3.5 & 4.5 & 4.5 & 4 \\
\hline
\end{tabular}

Table 5 contains all of the statistical data for all Tested scenarios and stages.

Table 5: Statistical Data about the Scores for all Tested Scenarios and Stages.

\begin{tabular}{|c|c|c|c|c|c|}
\hline & $\begin{array}{l}\text { Happiness } \\
\text { Before }\end{array}$ & $\begin{array}{l}\text { Happiness } \\
\text { After }\end{array}$ & $\begin{array}{l}\text { Engagement } \\
\text { Before }\end{array}$ & $\begin{array}{l}\text { Engagement } \\
\text { After }\end{array}$ & Age \\
\hline $\begin{array}{ll}\text { No. } & \text { of } \\
\text { observations } & \end{array}$ & 6 & 6 & 6 & 6 & 6 \\
\hline Minimum & 1 & 3 & 2 & 4 & 7 \\
\hline Maximum & 3 & 5 & 3 & 5 & 12 \\
\hline Median & 2 & 4 & 3 & 4 & 9 \\
\hline Mean (Average) & 1.83 & 4.00 & 2.58 & 4.08 & 9.17 \\
\hline Variance (n) & 0.47 & 0.33 & 0.12 & 0.12 & 2.81 \\
\hline $\begin{array}{l}\text { Standard } \\
\text { deviation (n) }\end{array}$ & 0.69 & 0.58 & 0.34 & 0.34 & 1.67 \\
\hline $\begin{array}{l}\text { Skewness } \\
\text { (Pearson) }\end{array}$ & 0.23 & 0.00 & -0.23 & -0.23 & 0.37 \\
\hline $\begin{array}{l}\text { Standard error of } \\
\text { the mean }\end{array}$ & 0.31 & 0.26 & 0.15 & 0.15 & 0.75 \\
\hline
\end{tabular}

The rate for Happiness and Engagement are calculated as follows: Value / 5*100 


\section{Results}

Two case studies were performed to test out the two main factors, which are engagement and happiness during lessons. Both case studies tested 6 special needs children of ages between 7 - 12 (two female and four male). As many variables were kept constant as possible between all testing scenarios. Figure 5 illustrates all of the scores for each student in the form of a bar graph (both before and after testing with robot).

The first stage tested for the student's performance. In the first scenario, the students were asked to identify road stop light signals. This was repeated several times for each student and an average was recorded. In the second scenario, the students are interactively taught road signals by the robot and then they are asked the same questions. It was found that the children all showed significant increases from $51.6 \%$ to $81.6 \%$ in the average student's engagement rate when comparing before and after robot intervention. These increases were calculated using data from Table 5. Increases in individual students' happiness are illustrated in Figure 5 for each student. Table 4 shows all of the individual scores for each student for Happiness, Video Surveillance, Test and Engagement.

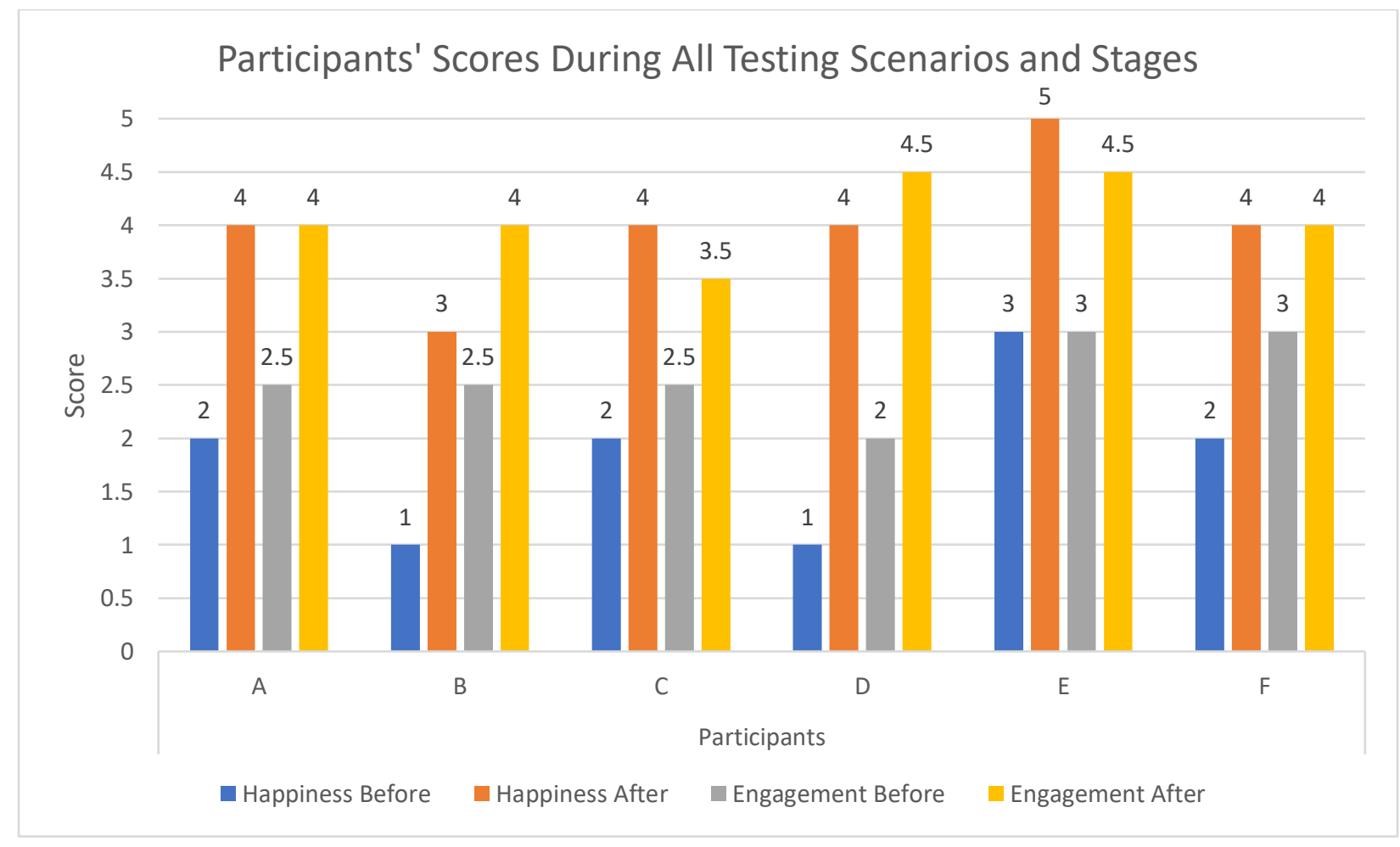

Figure 5: Participants' Scores During All Testing Scenarios and Stages.

In the second stage, the children were shown the robot doing a few exercises like dance moves, songs and stories to study how the student's engagement would change based on their facial expressions and the interactivity with the 
robot. It was found that the children were showing much more emotion and were even mimicking the moves of the robot, which is the complete opposite of how they were before interacting with the robot. This can be credited to the fact that the humanoid robot that was used in this experiment, NAO, has a much simpler face than a human and can only express emotions through the use of LEDs around his eyes. Another paper by (Kozima et al., 2009) has similar results to the ones shown here.

The third stage tests for the student's happiness. The students were first asked in the first scenario to complete a set of tasks and they were then asked to rate their happiness on a scale of 5. Then, the students take a course with the robot in the second scenario, where he teaches them about the subject and then asks them similar questions when they were not tutored by the robot. It was found that the children all showed significant increases from $36.6 \%$ to $80 \%$ in the average student's happiness rate when comparing before and after robot intervention. These increases were calculated using data from Table 5. Increases in individual students' happiness are illustrated in Figure 5 for each student.

After the experiments were completed, Table 5 containing all statistical data was created for all engagement and happiness scores. These statistics can be used to find trends in the results for interests' sake and for determining the type of data that was collected in this experiment (parametric or non-parametric). The type of data can be determined by comparing the median and the mean to the center of distribution of each data set; median for non-parametric and mean for parametric data types. For most of the data sets, it was found that the median more accurately represented the center of distribution, and since there was a small sample size (six), it is clear that the data is non parametric. To determine the significance of the difference between two non-parametric data sets, the Mann-Whitney U test must be used.

Table 6: Mann-Whitney U Test Comparing Happiness/ Engagement Before and After Robot Intervention.

Test A for Happiness

\begin{tabular}{llll}
\hline $\mathbf{U}$ & 0.5000 & $\mathrm{U}$ & 0.0000 \\
Expected value & 18.0000 & Expected value & 18.0000 \\
Variance (U) & 36.8182 & Variance (U) & 37.6364 \\
p-value (Two-tailed) & 0.0051 & p-value (Two-tailed) & 0.0043 \\
alpha & 0.05 & alpha & 0.05 \\
\hline
\end{tabular}

\section{Test B for Engagement}


Since the p-values for both Test A (0.0051) and B (0.0043) where lower than the alpha value of 0.05 as seen in Table 6, it can be concluded that the difference in happiness and engagement levels between before and after robot intervention are significant. The Pearson skewness and standard error from the mean were used to calculate and examine the consistency of the data. All of the skewness results were between -0.5 and 0.5 , showing that the skewness from the mean was very small / not significant. All of the standard errors from the mean were all under two standard deviations from the mean, showing that the standard error was small/ not significant. From the results, it can also be interpreted that gender and age does not affect the quality of the scores in anyway, but this claim may not be fully reliable due to the limited number of students that took part in this experiment.

\section{Conclusion}

The aim of paper is to check the viability of robots in improving autistic students' engagement and happiness, rather than just their performance. Six autistic students aged $7-12$ took part in this experiment (4 male and 2 female).

The students were tasked to take part in several scenarios that were used to determine scores for their happiness, test scores and a special metric called the video surveillance score. The video surveillance score was calculated using data relating to patterns in their behavior when performing the tasks. The test score and the video surveillance score were then combined to form the engagement score, which can accurately measure the student's performance in the tests as well as their overall interest in the subject. The tasks and scoring were then repeated again, but this time, the students were accompanied with the humanoid robot instructor NAO and their new scores were compared to the old ones. It was found that the children showed an improvement in the happiness rate from $36.6 \%$ to $80 \%$, and an increase in the engagement rate from $51.6 \%$ to $81.6 \%$. It was also found that the children were showing much more emotion and were much more responsive during the tasks. The results from the Pearson skewness and standard error from the mean showed that the data used in these experiments were consistent and the data was distributed closely to the mean. Gender and age did not seem to affect the scores in any way, but the numbers of the students were limited so this metric may not be fully reliable.

One of the biggest limitations of this research paper is the small number of students that took part in this experiment. This is due to the fact that there were not that many students in the center for special needs children, and of those children, only six children's families agreed to the requirements of this paper (recording and testing). 
For future work, we plan on having more students to test, using a more in-depth teaching technique, using a variety of other robots rather than just NAO for teaching special needs children and testing for a bigger variety of special needs students rather than just autism.

\section{Acknowledgment}

The research leading to these results did not receive grant funding.

\section{References}

[1]. Alemi, M., Meghdari, A., Basiri, N. M., \& Taheri, A. (2015). The effect of applying humanoid robots as teacher assistants to help Iranian autistic pupils learn English as a foreign language. Paper presented at the International Conference on Social Robotics.

[2]. Catalano, G. D., \& Catalano, K. J. J. o. E. E. (1999). Transformation: From teacher-centered to student-centered engineering education. 88(1), 59-64.

[3]. Chevalier, P., Li, J. J., Ainger, E., Alcorn, A. M., Babovic, S., Charisi, V., . . Evers, V. (2017). Dialogue design for a robot-based face-mirroring game to engage autistic children with emotional expressions. Paper presented at the International Conference on Social Robotics.

[4]. Chiluiza, D. F. P., Alcivar, N. I. S., \& Corredores, J. S. P. (2020). LOLY 1.0: A Proposed Human-Robot-Game Platform Architecture for the Engagement of Children with Autism in the Learning Process. Paper presented at the International Conference on Systems and Information Sciences.

[5]. Corporation, I. D. (2018). IDC - Global ICT Spending - Forecast 2018 - 2022.

[6]. Dimitrova, M., Wagatsuma, H., Tripathi, G. N., \& Ai, G. (2015). Adaptive and intuitive interactions with sociallycompetent pedagogical assistant robots. Paper presented at the 2015 International Conference on Information Technology Based Higher Education and Training (ITHET).

[7]. Hughes-Roberts, T., Brown, D., Standen, P., Desideri, L., Negrini, M., Rouame, A., .. Hasson, C. J. B. J. o. E. T. (2019). Examining engagement and achievement in learners with individual needs through robotic-based teaching sessions. 50(5), 2736-2750.

[8]. Ioannou, A., Kartapanis, I., \& Zaphiris, P. (2015). Social robots as co-therapists in autism therapy sessions: a single-case study. Paper presented at the International Conference on Social Robotics.

[9]. Kim, E. S., Berkovits, L. D., Bernier, E. P., Leyzberg, D., Shic, F., Paul, R., . . disorders, d. (2013). Social robots as embedded reinforcers of social behavior in children with autism. 43(5), 1038-1049.

[10].Kozima, H., Michalowski, M. P., \& Nakagawa, C. J. I. J. o. S. R. (2009). Keepon. 1(1), 3-18.

[11].Kozima, H., Nakagawa, C., \& Yasuda, Y. (2005). Interactive robots for communication-care: A case-study in autism therapy. Paper presented at the ROMAN 2005. IEEE International Workshop on Robot and Human Interactive Communication, 2005.

[12].Lowe, K. (2012). Effect of a humanoid robot during therapy on responding to joint attention with children with autism spectrum disorder.

[13].Nama, T., Deb, S., Debnath, B., \& Kumari, P. J. P. C. S. (2020). Designing a humanoid robot integrated Exer-LearningInteraction (ELI). 167, 1524-1532.

[14].Pakkar, R., Clabaugh, C., Lee, R., Deng, E., \& Mataricć, M. J. (2019). Designing a Socially Assistive Robot for LongTerm In-Home Use for Children with Autism Spectrum Disorders. Paper presented at the 2019 28th IEEE International Conference on Robot and Human Interactive Communication (RO-MAN).

[15].Pop, C. A., Simut, R. E., Pintea, S., Saldien, J., Rusu, A. S., Vanderfaeillie, J., . . Vanderborght, B. J. J. o. E. C. R. (2013). Social robots vs. computer display: Does the way social stories are delivered make a difference for their effectiveness on ASD children?, 49(3), 381-401.

[16].Saadatzi, M. N., Pennington, R. C., Welch, K. C., \& Graham, J. H. J. J. o. S. E. T. (2018). Effects of a robot peer on the acquisition and observational learning of sight words in young adults with autism spectrum disorder. 33(4), 284-296.

[17].Scassellati, B., Admoni, H., \& Matarić, M. J. A. r. o. b. e. (2012). Robots for use in autism research. 14.

[18].Scassellati, B., Boccanfuso, L., Huang, C.-M., Mademtzi, M., Qin, M., Salomons, N., . . . Shic, F. J. S. R. (2018). Improving social skills in children with ASD using a long-term, in-home social robot. 3(21).

[19].Scassellati, B., Brawer, J., Tsui, K., Nasihati Gilani, S., Malzkuhn, M., Manini, B., . . Shapiro, A. (2018). Teaching language to deaf infants with a robot and a virtual human. Paper presented at the Proceedings of the $2018 \mathrm{CHI}$ Conference on Human Factors in Computing Systems.

[20]. Statista. (2020). Prevalence of autism spectrum disorder among children in select countries worldwide as of 2020. https://www.statista.com/statistics/676354/autism-rate-among-children-select-countries-worldwide/ 
[21].So, W.-C., Wong, M. K.-Y., Lam, W.-Y., Cheng, C.-H., Ku, S.-Y., Lam, K.-Y., . . Wong, W.-L. J. R. i. D. D. (2019). Who is a better teacher for children with autism? Comparison of learning outcomes between robot-based and humanbased interventions in gestural production and recognition. 86, 62-75.

[22].Wang, H., Hsiao, P.-Y., \& Min, B.-C. (2016). Examine the Potential of Robots to Teach Autistic Children Emotional Concepts: A Preliminary Study. Paper presented at the International Conference on Social Robotics.

[23].YAMAN, Y., \& ŞIŞMAN, B. J. E. Ü. E. F. D. (2018). Robot Assistants in Education of Children with Autism: Interaction between the Robot and the Child. 21(1), 1-19.

[24]. Yousif, J. H., Kazem, H. A., Chaichan, M. T. J. I. J. o. C., \& Sciences, A. (2019). Evaluation Implementation of Humanoid Robot for Autistic Children: A Review. 6(1), 412-420.

[25].Zheng, Z., Zhang, L., Bekele, E., Swanson, A., Crittendon, J. A., Warren, Z., \& Sarkar, N. (2013). Impact of robotmediated interaction system on joint attention skills for children with autism. Paper presented at the 2013 IEEE 13 th International Conference on Rehabilitation Robotics (ICORR). 